RESEARCH REPORT

\title{
EXPLORING THE PHYSICAL ACTIVITY KNOWLEDGE AND PROMOTION AMONG PHYSICAL THERAPISTS
}

\begin{abstract}
\section{BACKGROUND AND AIMS}

Globally physical inactivity is recognized as a primary concern and one of the major risk factor associated with long term disability. Health professionals are expected to promote active lifestyle but are neglecting it. Therefore it is essential to explore the knowledge of physical therapist regarding activity and promotion.
\end{abstract}

\section{METHODOLOGY}

A cross-sectional survey was conducted among 153 physical therapist at different tertiary care hospitals of Karachi where dominant group was females $(n=102)$. A self-administered questionnaire was distributed through convenience sampling after obtaining consent to evaluate their knowledge regarding physical activity recommendation by American College of Sports Medicine and there awareness among their patients.

\section{RESULTS}

Only $8.5 \%$ of physiotherapists correctly answered all three questions regarding Physical activity; guidelines. Promoting physical activity through their practice, only $54 \%$ of PT initiate conversation, $28 \%$ formally assess their patients, while brief intervention was given by only $31 \%$.

\section{CONCLUSION}

It was concluded that knowledge regarding PA was compromised; with a lack of awareness about recommended guidelines for physical activity was also found.

\section{KEYWORDS}

Physical Activity, Knowledge, Physical Fitness, Exercise, Physical Therapist, Physical Inactivity.

\author{
Naveed Qamar \\ Physiotherapist \\ Agha Khan University Hospital \\ naveedqamar71@yahoo.com
}

[Qamar N. Exploring the Physical Activity Knowledge and Promotion among Physical Therapists. Pak. j. rehabil 2019;8(2):19-25] 


\section{INTRODUCTION}

According to World Health Organization (WHO), Physical Activity (PA) is characterized by any bodily movement caused by skeletal muscles that needed energy expenditure (WHO, 2019)'. Physical activity on the basis of daily routine reduces $20 \%$ to $30 \%$ mortality risk due to any causes, in comparison to those having inadequate activity ${ }^{2}$. A study claimed that $38 \%$ of physically inactive people spend more days in hospital and use remarkably more healthcare resources as compared to the active people ${ }^{3}$. The worldwide fifth leading risk of death is overweight and obesity, each year around 3 million adult populations die due to obesity ${ }^{4}$. As per the National Health Survey of Pakistan (1990-1994), overweight and obesity prevalence were measured at $25 \%$ and over $10 \%$ respectively ${ }^{5}$. Researches shows that overweight are specifically associated to cardiovascular disease 6 . However, many researchers suggested that this increase weight can be reduced significantly by physically active life style ${ }^{2,7}$. Furthermore, active life style promotion in general population is an essential tool to prevent numerous consequences of metabolic syndrome that has been difficult to manage in the past ${ }^{8}$. Importance of PA to health is increased by evidence and it has led to the calls for worldwide physical activity policies and to the promotion of physical activity as a medicine agenda ${ }^{9,10}$.

American College of Sports Medicine (ACSM) and American Heart Association (AHA) synthesize the recommended level of physical activity for the prevention of metabolic and cardiovascular disease. ACSM released the first form of physical activity recommendation for adults in $1975^{11}$. Later in 1995, the physical activity was being recommended for at least 30 min moderate to vigorous, preferred on all days of week ${ }^{12}$. Whereas in 1996, England's department of health followed the same guidelines provided by ACSM and suggest 30 min of moderate to vigorous physical activity on at least 5 days/week ${ }^{13}$. In 2008, federal government issued physical activity guidelines for Americans and was published after expert's review of scientific data. This was first to state recommended guidelines specifically as $150 \mathrm{~min} /$ week with moderate to vigorous physical activity ${ }^{14}$. The recent report of UK Chief Medical Officer on physical activity has again draw attention on the possible benefits to public health if we fulfill the physical activity guidelines. The same format was also issued by World Health Organization that used in global physical activity guidelines' Nevertheless, health care practitioners are considerably supposed to promote the physical activity as a public health awareness measure. The health care contact is a chance to positively affect a patient's health and it is mostly done through short duration interventions. These short interventions can be done in routine health care consultations, and also it has the tendency to approach large propor- tion of the adult population and it has also shown to be cost effective ${ }^{15,16}$.

The physical therapists are primary care practitioners having pronounced potential for physical activity promotions ${ }^{17}$. Now a days, physical therapy is considered as a tertiary prevention discipline, as physical therapist are provided with special skills and potential in order to prevent the condition. Knowledge of guidelines is an essential pre-cursor to bring change in general population health and it will help in understanding the correlate of effective health promotion intervention. There is substantial literature that supports significance of physical activity that emphasizes to promote primary and secondary prevention of many chronic conditions. By knowing the importance of knowledge of physical activity guidelines provided by ACSM, previous researches mainly done in order to know the knowledge of guidelines. A survey done in UK regarding the awareness of physical activity recommendation by ACSM guidelines on 2381 participants concluded that only a third of respondents know the recommended guidelines of physical activity, more over it was demonstrated that there is no widespread knowledge of physical activity guidelines concluded the lack of awareness in $0.56-36.1 \%$ individuals $^{18}$. Moreover, there was no global awareness of national physical activity recommendations. These results highlighted the requirement to promote physical activity through effective campaigns 18. It is thought that physical therapist should participate in promotion of physical activity, but the views of physical therapist regarding their role in this are not well known. Thus the acceptability and feasibility of physical activity promotion is needed to be explored in physical therapy setting. To date, we have no research conducted on how much physical therapist is aware of physical activity guidelines recommended by ACSM in Pakistan, particularly in Karachi. Therefore, aim of this study is to assess the knowledge of PA guidelines among physiotherapists and how much they are promoting physical activity among patient.

\section{METHODOLOGY}

\section{Study Setting}

The Study was conducted at different tertiary care hospitals of Karachi, Pakistan.

\section{Target Population}

Qualified Physical Therapists with both undergraduate and postgraduate programs were included in the study.

\section{Study Design}

A cross-sectional design was selected for the study.

\section{Duration of Study}

Data was collected after six months of approval of synopsis. 
Sampling Technique

Non-probability, convenient sampling technique was used.

\section{Sample Selection}

\section{Inclusion Criteria}

- Physical therapist with minimum one year of experience working at primary, secondary and tertiary care, community based, and working as an academician at a reputed institution ${ }^{19}$.

\section{Exclusion Criteria}

- House Officers.

- Other health care professionals.

\section{Data Collection Procedure}

A total of 153 individuals were enrolled in the study including 51 males and 102 females, working as academician or clinician in different health care setups of Karachi including primary, secondary and tertiary care hospitals for at least a year. Two qualified physical therapists were trained and then assigned for collecting the data. The data was collected as per the convenience of the PTs and their busy schedule. Well known Hospitals from different districts of Karachi were approached to recruit PTs. On each visit to hospital, firstly, permission letter was taken followed by signing a written consent subjected to the agreement of PT and the hospital administration. PTs were asked to fill the questionnaire that includes questions regarding the knowledge of physical activity guidelines provided by American College of Sports Medicine and its promotion to their patients. Moreover, the questionnaire also included demographic data that helped the researcher to eliminate the person not meeting the inclusion criteria. After completion of questionnaire, researcher proceeded towards the analysis.

\section{Data Collection Tool}

A self-designed questionnaire was used in the study. The first section of questionnaire consists of screening questions, to identify the participants as per our inclusion criteria. The next section comprised of 11 questions. All questions were close ended provided with multiple options. This section assessed physiotherapist's knowledge regarding physical activity guidelines recommended by ACSM and their frequency of assessment and promotion of patient for brief interventions of physical activity.

\section{Data Analysis Strategy}

Data was entered and analyzed on SPSS (Statistical Package for Social Science) version 2.0. Participant's demographic characteristics and responses were analyzed using descriptive statistics in terms of frequency and percentage.

\section{Ethical Considerations}

All participants' identity and obtained information kept confidential under researcher supervision. The participants was respected and seen not as a passive source to be a part of this research. Before the commencement of study, informed consent obtained from each participant so that they had known the possible risks and benefits to participate as well as their potential contribution towards it.

\section{RESULTS}

\section{Demographic Details}

There were total 153 respondents to the survey screened according to inclusion criteria, where dominancy was found among females $n=102$. Most of the therapist were young adults $(n=102)$ showing that they are in their initial stages of the career. Almost $30 \%$ of PTs were in the middle adulthood (Table 1).

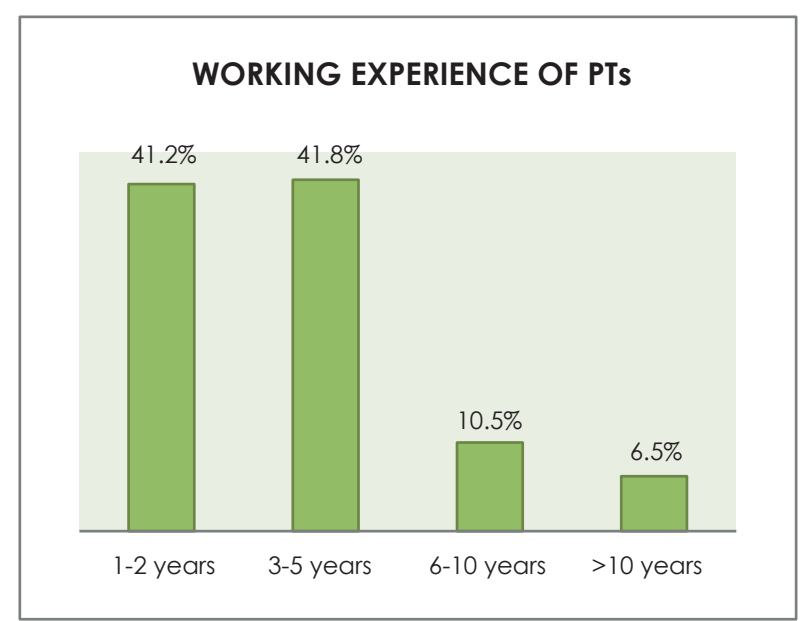

Figure.1 Years of experience of physiotherapists

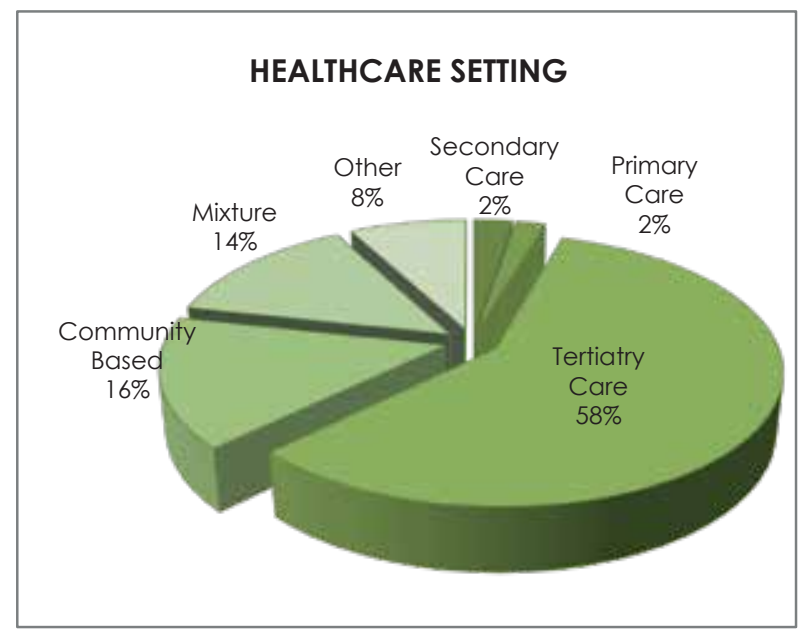

Figure.2 Percentage of Health care setting of Physical Therapists 
Table 1. Demographics and professional details of Participants.

\begin{tabular}{|lc|}
\hline Gender & $\mathrm{n}=153(\%)$ \\
\hline Female & $51(33.3)$ \\
\hline Age & $102(66.6)$ \\
\hline$<30$ & $102(66.6)$ \\
\hline $\mathbf{4 0}-\mathbf{4 9}$ & $33(21.5)$ \\
\hline Qualification & $14(9.1)$ \\
\hline BSPT, ADPT & $4(2.6)$ \\
\hline BSPT, ADPT, MS & $11(7.1)$ \\
\hline Position & $31(20.2)$ \\
\hline Senior physiotherapist & $68(44.4)$ \\
\hline Senior Lecturer & $27(17.6)$ \\
\hline & $16(10.4)$ \\
\hline
\end{tabular}

Participants reported a range of years of experience with $41.2 \%(n=63)$ of the sample having $1-2$ years of experience, $41.8 \%(n=64)$ having $3-5$ years of experience, $10.5 \%(n=16)$ had $6-10$ years of experience and only $6.5 \%(n=10)$ had more 10 years of experience (Figure 1).

The PTs were asked to mention the health care setting where they work. The majority of respondents $58 \%$ were working in tertiary care hospitals, $16 \%$ was working at community based, $14 \%$ were those who worked as academician and clinician as well, $2 \%$ of primary care and $2 \%$ of secondary care respectively and $8 \%$ comprised of others (Figure 2).

\section{Promotion of Physical Activity}

Physical therapist was asked to approximate the frequency of promotion of physical activity, and it was estimated through specific questions related to promotion as illustrated in Figure 3. It was revealed that only about 35\% of physiotherapists initiate conversation about PA with their patients. On the other hand, $18 \%$ physical therapists assess the level of physical inactivity in their patients and $20 \%$ of physical therapist took essential steps for brief intervention of physical activity among physically inactive patients. Moreover $12 \%$ physical therapist spread awareness through socially connecting their patient about the physical activity.

\section{Knowledge of Physical Activity Guidelines}

Forty nine percent of respondent physiotherapist $(n=75)$ reported that they are aware of PA guidelines given by ACSM but concluded result was found different. Numbers of correct answers to specific questions shows that only $8.5 \%$ of respondent's physiotherapist correctly answered all three questions. The minutes of moderate intensity of physical activity per week for adults was answered correctly by only $8.5 \%(n=13)$, whereas minutes of vigorous physical activity recommended per week for adults was correctly answered by $28 \%(n=43)$ and the days per week required to do strength training for adults was correctly answered by $29.4 \%(n=45)$.

\section{Physical Therapist Activity Level}

Table 2. Showing no. of correct answers to PA guideline

\begin{tabular}{|l|c|c|}
\hline $\begin{array}{c}\text { Physical Activity } \\
\text { Guideline Questions }\end{array}$ & $\begin{array}{c}\text { No. of } \\
\text { Correct } \\
\text { responses }\end{array}$ & $\%$ \\
\hline $\begin{array}{l}\text { How many minutes of } \\
\text { moderate intensity } \\
\text { physical activity } \\
\text { are recommended } \\
\text { per week for adults? }\end{array}$ & 13 & 8.5 \\
\hline $\begin{array}{l}\text { How many minutes of } \\
\text { vigorous intensity } \\
\text { physical activity are } \\
\text { recommended per } \\
\text { week for adults? }\end{array}$ & 43 & 28 \\
\hline $\begin{array}{l}\text { How many days } \\
\text { per week it is } \\
\text { recommended that } \\
\text { adults do strength } \\
\text { training? }\end{array}$ & 45 & 29.4 \\
\hline
\end{tabular}

Physical Therapist was asked about their PA level over a week for at least 30 min per day. It was analyzed that only $12.4 \%(n=19)$ physical therapist do PA for $30 \mathrm{~min} /$ day for 5 days. However, $22.9 \%$ Physical therapist are not willing to perform PA throughout week, that is an alarming sign for our PTs. Figure 3 illustrated in detail the physical therapist own habit of PA. 


\section{PHYSIOTHERAPISTS PHYSICAL ACTIVITY}

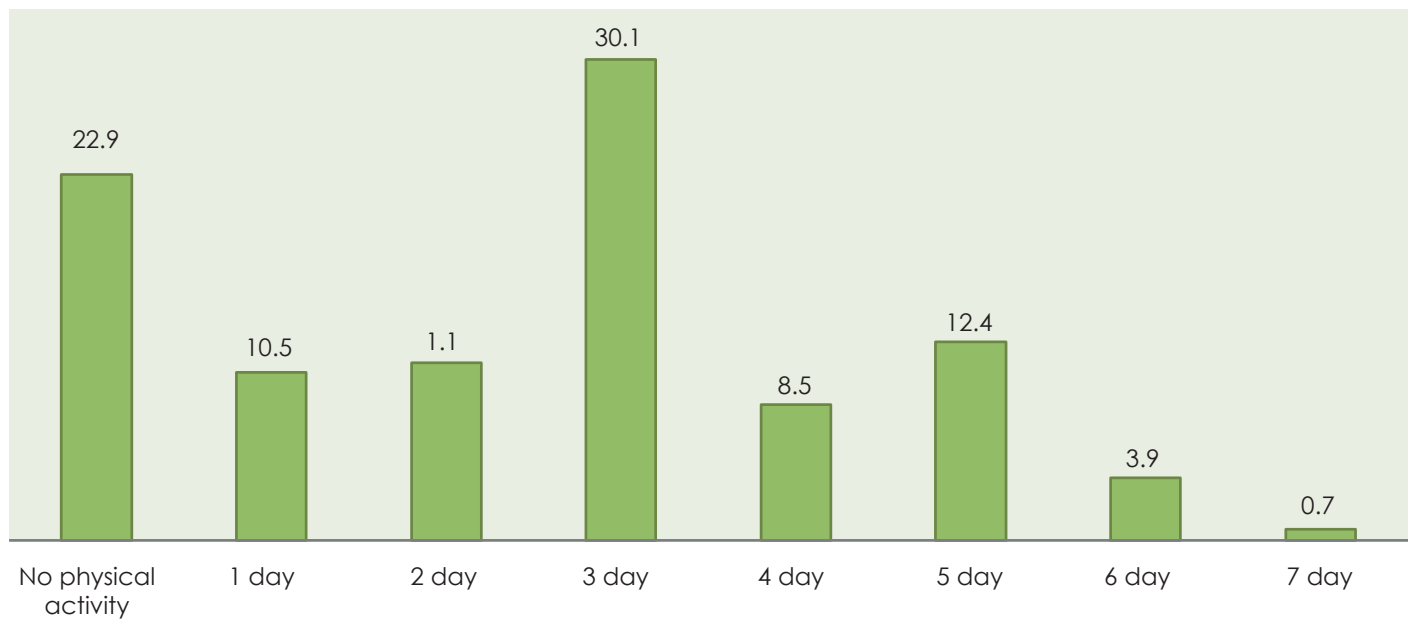

No. of days performing physical activity for atleast 30 minutes

Figure 3. Representing physiotherapist's own PA during last week in percentage

\section{DISCUSSION}

The present study shows that physical therapist has an important role in prescribing physical activity to improve activity limitation and participant restriction. The brief counseling session was found to be the easy and feasible way of health promotion. Moreover, the study also revealed that role of physical therapist was compromised in prescribing as well as performing the PA. There is a significant lack of PA guideline knowledge recommended by ACSM for routine physical activity among PTs. Results from our study showed that only $8.5 \%$ of physiotherapists correctly answered questions related to ACSM guidelines for physical activity. This increases the need of adding the guidelines in either the academic curriculum or improves the evidence based clinical practice. Majority of participants incorporates some form of discussion of physical activity with their patients. However, physical activity is not regularly assessed and there is no regular delivery of brief treatments resulting in weak knowledge regarding the exercise based physical activity programs. Moreover, this actually highlights the need of evidence based clinical practice especially when prescribing physical activity. Despite the knowledge disparity, most participants reported feeling confident that they are aware of guidelines and promote the physical activity to patients. It is primarily the responsibility of public health professionals and stakeholder groups to implement these recommendations that mostly use traditional methods of health promotion. A cross-sectional survey ${ }^{20}$ conducted in Ireland, assessed the knowledge of PA guidelines among general practitioners and physiotherapists, found that more physiotherapist were aware of knowledge than general practitioners who correctly reported the minimal activity guidelines. Physical activity must be of adequate length, frequency and intensity to be effective for health. At least 150 minutes of moderate intensity of exercise that adults should do per week is recommended highly recommended in Europe ${ }^{21}$. Previously, in another survey the prevalence of knowledge of current guidelines (that was introduced in 2011) were compared with previous guidelines in two large samples of UK ${ }^{22}$. It was found that $18 \%$ of participants accurately know the physical activity guidelines whereas $11 \%$ of previous surveys conducted in 2007 accurately know the guidelines. Moreover, a Canadian study also emphasized on improving and creating the awareness among general adult population, revealed that almost $12.9 \%$ of Canadian adults were aware of PA guidelines ${ }^{23}$.

On the other hand, a consistency of low level of knowledge is also found in general practitioners of England; their analysis revealed that only $20 \%$ of GP are familiar with PA guidelines ${ }^{24}$ that may ultimately lead to obesity, chronic diseases, depression and anxiety. In spite of well reported guidelines and benefits of physical activity, the survey of England showed only $39 \%$ of male and $29 \%$ of female fulfill the recommended level of physical activity ${ }^{25}$. Globally, sedentary life style for last decade has been alarming throughout all ages therefore the central aspect of health promotion is changing by the role of primary care and general practitioners ${ }^{26}$. They are trained in their places to promote health among inactive population. However, previous literature has shown that guidelines should also be modified according to the needs and ethnicity. Our results were found to be consistent with that of Lowe et al 2017 where only $16 \%$ physiotherapist correctly answered PA guideline questions ${ }^{19}$. Almost $68 \%$ of 
physiotherapist routinely provides intervention for Physical inactivity whereas in our study $31 \%$ offer intervention. This raises questions regarding health of people. It is important for our health professionals to implement ACSM guidelines that are available for all age group with or without co morbidities even. As it has been estimate that as the life expectancy is increasing that would increase more disabilities among the older aged population making them more disabled.

Researchers have been keen to not only promote the physical activity but to also implement the evidence based practice among the practitioners of health care. Since the last two decades a number of researches were conducted mostly in the western countries yet there is a lack of registered data regarding the promotion and implementation of PA on national level. A study from Pakistan $^{27}$ analyzes the physical inactivity in obese people and their barriers to physical activity. Lack of counseling by health care providers was among their multiple barriers. Physical activity levels of students in a medical college have also been highlighted. Only $11.5 \%$ of students were found to be physically active. This quite similar to our physiotherapist physical activity routine that is $12.4 \%$. The consistency in decrease level of physical activity among people will raise health issues in future. This not only highlights the need of curriculum revision and counseling among these students but also to create practical sessions, workshops and conferences to implement it. Our research was only limited to few health care institutes of Karachi therefore recommendations to do it on a larger scale considering other health care professionals. According to the American College of Sports Medicine guidelines, 150 minute per week of moderate intensity of walking is highly recommended ${ }^{28}$ that is unfortunately neither recommended by the practitioners nor taught by the academician's. Therefore, different campaigns and program aids should be planned to decrease the non-communicable diseases.

\section{CONCLUSION}

The results of our study found lack of knowledge among the physical therapist of Karachi, Pakistan. Although healthcare professional are expected to improve the physical fitness and motivate the patients but our study shows that this element is missing or neglected. However, the ACSM guidelines are quite old still either the therapist are unaware or are not practicing it. Therefore, it arise the need to recall the guidelines and to promote physical activity among general population. Furthermore, studies are required in context to promote the knowledge of physical activity among health professionals. Sedentary life style is increasing day by day with urban development and globalization. While considering the outcomes of this physical inactivity, it is important to promote the physical activity in our population. The study contributed role towards the awareness among healthcare professionals about recommended guidelines of physical activity and its promotion among patients.

\section{REFERENCES}

[1] World Health Organization. (2019). The Global Strategy on Diet, Physical Activity and Health (DPAS). [online] Available at: https://www.who.int/nmh/wha/59/dpas/en/ [Accessed 29 May 2018].

[2] Physical Activity [internet]. World Health Organization. 2018.

[3] Ma J, Pender M, Welch M. Education Pays 2016: The Benefits of Higher Education for Individuals and Society. Trends in Higher Education Series. College Board. $2016 .$.

[4] World Health Organization. (2018). Obesity and overweight. [online] Available at: https://www.who.int/news-room/fact-sheets/detail/obesity-and-overweight 2018.

[5] Jafari-Adli S, Jouyandeh Z, Qorbani M, Soroush A, Larijani B, Hasani-Ranjbar S. Prevalence of obesity and overweight in adults and children in Iran; a systematic review. J Diabetes Metab Syndr. $2014 ; 13(1): 121$.

[6] Mehri A, Solhi M, Garmaroudi G, Nadrian H, Sighaldeh SS. Health promoting lifestyle and its determinants among university students in Sabzevar, Iran. Int J Prev Med. 2016;7.

[7] Hoeger WW, Hoeger SA, Hoeger Cl, Fawson AL. Lifetime physical fitness and wellness. Cengage Learning; 2018.

[8] Heredia NI, Lee M, Reininger BM. Exposure to a community-wide campaign is associated with physical activity and sedentary behavior among Hispanic adults on the Texas-Mexico border. BMC public health. $2017 ; 17(1): 883$.

[9] Kohl 3rd HW, Craig CL, Lambert EV, Inove S, Alkandari JR, Leetongin G, Kahlmeier S, Lancet Physical Activity Series Working Group. The pandemic of physical inactivity: global action for public health. The lancet. 2012 $21 ; 380(9838): 294-305$.

[10] Myers J, McAuley P, Lavie CJ, Despres JP, Arena R, Kokkinos P. Physical activity and cardiorespiratory fitness as major markers of cardiovascular risk: their independent and interwoven importance to health status. Prog Cardiovasc Dis. $2015 ; 57(4): 306-14$.

[11] Foster C. Guidelines for Graded Exercise Testing and Exercise Prescription, Philadelphia, Lea \&Febiger, 1980. J Cardiopulm Rehabil Prev. $1981 ; 1$ (5).

[12] Gill DL, Williams L, Reifsteck EJ. Psychological dynamics of sport and exercise. J. Hum. Kinet.; 201723.

[13] Chatfield SL, Hallam JS. Flipping the on switch: Men who became regularly physically active during middle age. J Sport Exercise Psy. 2016 ; 14(4):340-52. 
[14] Kay MC, Carroll DD, Carlson SA, Fulton JE. Awareness and knowledge of the 2008 Physical Activity Guidelines for Americans. Journal of Physical Activity and Health. 2014 May $1 ; 11(4): 693-8$.

[15] Vijay GC, Wilson EC, Suhrcke M, Hardeman W, Sutton S. Are brief interventions to increase physical activity cost-effective? A systematic review. Br J Sports Med. $2016 ; 50(7): 408-17$.

[16] Pears S, Morton K, Bijker M, Sutton S, Hardeman W. Development and feasibility study of very brief interventions for physical activity in primary care. BMC public health. 2015;15(1):333.

[17] Hinze CJ, Davenport TE, Jewell DV. Physical Therapy and the Built Environment: New Strategies to Deploy Existing Expertise in the Human Movement System. HPA Resource. 2018 ;18(3).

[18] Kay MC, Carroll DD, Carlson SA, Fulton JE. Awareness and knowledge of the 2008 Physical Activity Guidelines for Americans. J Phys Activ Health. 2014;11 (4):693-8.

[19] Lowe A, Littlewood C, McLean S, Kilner K. Physiotherapy and physical activity: a cross-sectional survey exploring physical activity promotion, knowledge of physical activity guidelines and the physical activity habits of UK physiotherapists. BMJ open sport \& exercise medicine. $2017 ; 3(1): e 000290$.

[20] Barrett EM, Darker CD, Hussey J. Promotion of physical activity in primary care: knowledge and practice of general practitioners and physiotherapists. Int. J. Public Health. 2013 ;21 (1):63-9.

[21] Pringle A, Zwolinsky S, McKenna J, Robertson S, Daly-Smith A, White A. Health improvement for men and hard-to-engage-men delivered in English Premier League football clubs. Health education research. $2014 ; 29(3): 503-20$.

[22] Hunter RF, Tully MA, Donnelly P, Stevenson M, Kee F. Knowledge of UK physical activity guidelines: Implications for better targeted health promotion. Preventive medicine. 2014 ;65:33-9.

[23] Dale LP, LeBlanc AG, Orr K, Berry T, Deshpande S, Latimer-Cheung AE, O'Reilly N, Rhodes RE, Tremblay MS, Faulkner G. Canadian physical activity guidelines for adults: are Canadians aware?. Appl Physiol Nutr Me. 2016:41(9):1008-11.

[24] Chatterjee R, Chapman T, Brannan MG, Varney J. GPs' knowledge, use, and confidence in national physical activity and health guidelines and tools: a questionnaire-based survey of general practice in England. Br J Gen Pract. $2017 ; 67(663):$ e668-75.

[25] O'Donovan G, Hillsdon M, Ukoumunne OC, Stamatakis E, Hamer M. Objectively measured physical activity, cardiorespiratory fitness and cardiometabolic risk factors in the Health Survey for England. Am. J. Prev. Med.. 2013 ;57(3):201-5.

[26] Okie S. The evolving primary care physician. N Engl J Med. $2012 ; 366(20): 1849-53$.

Del Mar Bibiloni M, Coll JL, Pich J, Pons A, Tur

[27] JA. Body image satisfaction and weight concerns among a Mediterranean adult population. BMC public health. $2017 ; 17(1): 39$.

[28] American College of Sports Medicine. ACSM's guidelines for exercise testing and prescription. Lippincott Williams \& Wilkins; 2013. 